\title{
Modeling the Impacts of Boreal Deforestation on the Near-Surface Temperature in European Russia
}

\author{
Zhihui Li, ${ }^{1,2,3}$ Xiangzheng Deng, ${ }^{1,3}$ Qingling Shi, ${ }^{1,3}$ Xinli Ke, ${ }^{4}$ and Yingcheng Liu ${ }^{5}$ \\ ${ }^{1}$ Institute of Geographic Sciences and Natural Resources Research, Chinese Academy of Sciences, Beijing 100101, China \\ ${ }^{2}$ University of Chinese Academy of Sciences, Beijing 100049, China \\ ${ }^{3}$ Center for Chinese Agricultural Policy, Chinese Academy of Sciences, Beijing 100101, China \\ ${ }^{4}$ College of Land Management, Huazhong Agricultural University, Wuhan 430070, China \\ ${ }^{5}$ Faculty of Resource and Environmental Science, Hubei University, Wuhan 430062, China
}

Correspondence should be addressed to Xiangzheng Deng; dengxz.ccap@gmail.com

Received 9 July 2013; Revised 2 September 2013; Accepted 26 September 2013

Academic Editor: Burak Güneralp

Copyright (c) 2013 Zhihui Li et al. This is an open access article distributed under the Creative Commons Attribution License, which permits unrestricted use, distribution, and reproduction in any medium, provided the original work is properly cited.

Boreal deforestation plays an important role in affecting regional and global climate. In this study, the regional temperature variation induced by future boreal deforestation in European Russia boreal forest region was simulated based on future land cover change and the Weather Research and Forecasting (WRF) model. This study firstly tested and validated the simulation results of the WRF model. Then the land cover datasets in different years (2000 as baseline year, 2010, and 2100) was used in the WRF model to explore the impacts of boreal deforestation on the near-surface temperature. The results indicated that the WRF model has good ability to simulate the temperature change in European Russia. The land cover change in European Russia boreal forest region, which will be characterized by the conversion from boreal forests to croplands (boreal deforestation) in the future 100 years, will lead to significant change of the near-surface temperature. The regional annual temperature will decrease by $0.58^{\circ} \mathrm{C}$ in the future 100 years, resulting in cooling effects to some extent and making the near-surface temperature decrease in most seasons except the spring.

\section{Introduction}

According to the fourth assessment report of Intergovernmental Panel on Climate Change (2007, IPCC AR4), there is a probability of more than 90 percent that human activities have affected the climate [1], mainly through two approaches: fossil fuel burning and land cover change. There is a consensus among the scientists that fossil fuel burning can lead to increase in the greenhouse gas concentration in the atmosphere and further results in the global warming, while the impacts of land cover change on the climate system at the local, regional, and global scales have become one of the research hotspots. Terrestrial land cover is an important component of the climate system. It is the most direct source not only of the atmospheric heat, but also of the atmospheric moisture. Therefore, land cover change will directly affect the surface-atmosphere interactions and further influence the atmospheric thermodynamic characteristics. The land use activities significantly changed the regional land cover and exerted great impacts on the climate system at regional scale, including temperature, evapotranspiration, precipitation, wind, and air pressure. The impacts of land cover change on climate can be divided into two major categories, that is, biogeochemical and biogeophysical impacts [2]. The biogeochemical processes mainly refer to greenhouse gas emissions caused by the land cover change, changing the gas composition of the atmosphere and thereby affecting the climate. The biogeophysical processes directly affect the physical parameters that determine the absorption and disposition of energy at the earth's surface.

Global deforestation plays an important role in regulating climate through biogeophysical effects [3]. At present, deforestation is one of the most important types of land cover change, and the global land cover change associated with deforestation has always been taken as the main reason for the climate change in different regions. The albedo for forests is relatively lower than that for grasslands or 
croplands, thus forests can absorb more solar radiation [4]. And the transpiration of forests is more exuberant than that of herbaceous plants in the growing season and will release more latent heat. Forest cover change may cause the change of the albedo and evapotranspiration and consequently leads to climate change. These effects on climate are not the same at different latitudes. Tropical forests have strong evapotranspiration, deforestation in tropical forests such as the Amazon region will lead to lower evaporate rates and make the local climate become drier and warmer [5-8]. Deforestation at high latitudes, that is, deforestation in boreal forests has different effects on the climate compared with that in tropical regions $[3,9,10]$.

There have been many researches focusing on the impacts of the high-latitude boreal deforestation on climate change. As boreal forest is the largest continuous terrestrial ecosystem in the world, boreal forest has the potential to influence the climate by altering the radiation budget. Bonan found that loss of boreal forests provided a positive feedback for glaciation, whereas boreal forest expansion during the midHolocene amplified warming [3]. Bathiany et al. clarified that in the next 100 years, the deforestation at the northern latitudes $\left(45^{\circ} \mathrm{N}-90^{\circ} \mathrm{N}\right)$ will lead a decrease of $0.25^{\circ} \mathrm{C}$ in global annual mean temperature, while the afforestation had equally large warming effects combining both biochemical and biophysical effects [9]. And through latitude-specific large-scale deforestation experiment, Bala et al. revealed that the difference of the global average temperature between the standard case without deforestation and the experiment with boreal deforestation at high latitude in year 2100 is $-0.8^{\circ} \mathrm{C}$ [11]. Based on observations, Lee et al. found that, for the site pairs at $45^{\circ} \mathrm{N}$, the mean annual temperature difference induced by deforestation is $0.85 \pm 0.44^{\circ} \mathrm{C}$ ( \pm mean standard deviation) [12]. Overall, most researches clarified that, at higher latitudes, boreal deforestation will result in cooling effects due to the boreal forests with lower albedo being replaced by other types of vegetation with higher albedo, such as crops and grasslands [13]. Boreal deforestation will lead to a large increase in albedo especially in winter [14], the alteration of albedo is a major factor driving climate change, which will alter surface heat balance. Also boreal deforestation can alter surface heat balance by altering evaporative heat transfer caused by evapotranspiration from vegetation and by changes in surface roughness [15]. Unlike the tropical forests, removal of the boreal forest vegetation has a larger effect that resulted from the strong albedo feedback than from the evapotranspiration change on the surface radiative balance. In boreal forest region, the considerable increase in albedo due to deforestation will result in cooling effects since the albedo plays a more important role than the vegetation transpiration [16-18]. Replacing the forest vegetation with other types of vegetation or bare ground that will be snow covered increases the albedo considerably. The land surface responds by absorbing less net radiation as more incoming solar radiation is reflected from the surface. The air temperature at the surface will cool considerably as there is less energy absorbed at the surface [19].

As to the selection of climate models and experiment designs to detect the climate impact of deforestation, current researches on the impacts of boreal forests change on climate change mainly focus on large-scale experiments based on global or regional climate models, with assumption that the boreal forests are being replaced by other types of vegetation or bare lands $[10,19]$, while only a few researches implemented simulation of the climate effects of future land cover change based on the scenario analysis with a mesoscale numerical model. The earliest researches on the regional climate effects generally used the global circulation models (GCMs) and carried out the sensitivity test with the forceresponse method $[20,21]$, that is, representing the land use changes with the changes of the land surface parameters (e.g., albedo, roughness, and evapotranspiration). The GCMs have been widely used in the study of climate change; however, their coarse resolution is inappropriate to reveal the land surface-atmosphere interactions for simulating regional climate variability especially for complex terrain, so there are some bias and uncertainties in the simulation of the regional climate change with GCMs [22, 23]. Then regional climate models (RCMs) were developed during the late 1980s and the early 1990s [24] and have become an important tool in the regional climate simulations, among which, Weather Research and Forecasting (WRF) model represents the recent advances of RCMs that combine the expertise and experience for mesoscale meteorology and land-surface and climate science developed over the last several decades [25]. The WRF model was specifically designed for high resolution applications and provides an ideal tool for assessing the value of high resolution regional climate modeling, and some researchers have identified the WRF to be superior to other RCMs [23, 26, 27]. In addition, although the experiments with assumption that the boreal forest be completely replaced by other types of vegetation can help understand the impact mechanism of boreal deforestation, experiments based on land cover scenarios can relatively be related to real human activities and provide reference for future land use management.

European Russia with high coverage of boreal forest has gone through intensive human activities. The largest part of the boreal forests is located in Russia, and about half of the boreal forests are still primary, with very limited impacts from forestry and other human activities. While in Scandinavia and western Russia (European Russia), the boreal forests are most intensely managed and influenced by human beings with only patches of old-growth forests remain in reserves. Some researchers have shown that European Russia has gone through fluctuant forest cover change [2830]. Baumann et al. found that the temperate forests in European Russia underwent substantial change during 19902010, with a decrease rate of $1 \%$ in total area between 1990 and 1995 and an increase rate of 1.4\% between 2005 and 2010, which may be caused by the forest regrowth on abandoned farmlands [28]. Hansen et al. reported that Russia has the third largest area of gross forest cover loss (GFCL). Russia's GFCL is geographically widespread due to deforestation in the European and far-eastern parts of the country and forest fires throughout Siberia [29]. Potapov et al. indicated that the forest cover in the central part of European Russia was between $16 \%$ and $50 \%$ (average forest cover of 36\%). The low forest cover within these regions is a result of a long history 


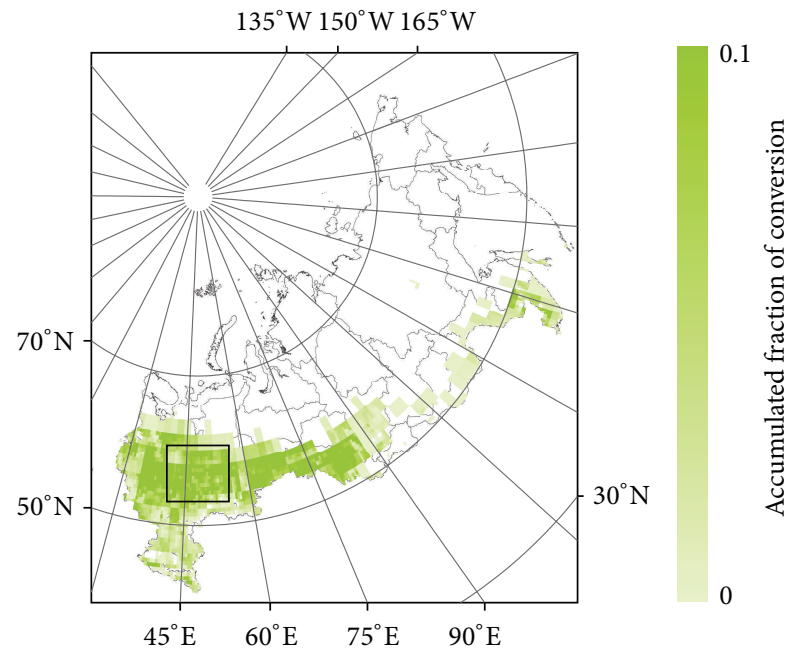

FIgURE 1: Accumulated fraction of conversion from forests to croplands between 2000 and 2100 in the study area. The black box is the boundary of the study area.

of conversion of forests to croplands. The forest cover is the lowest (3-14\%) in eleven administrative regions located in the forest-steppe interface, where the expansion of croplands was coupled with the natural forest fragmentation [30].

Thus, in this study, the European Russia that has experienced fluctuant land cover change and serious forest loss due to the intensive human activities was selected as a typical area to detect the impacts of deforestation on the near-surface temperature (Figure 1). And the near-surface temperature in European Russia was simulated with the Weather Research and Forecasting Model (WRF) on the basis of the land cover datasets of years 2000, 2010, and 2100, which were derived from the scenarios of land cover change. The results can contribute to the understanding of biogeophysical effects of boreal forest change on the climate and provide constructive suggestions on the future climate mitigation and land use management of European Russia.

\section{Data and Methodology}

2.1. Data Processing. The data used in this study include land cover data, atmospheric forcing data, and meteorological observation data. The accuracy and resolution of land cover data are significant to the climate simulation [31]. In this study, the $1 \mathrm{~km}$ resolution land cover data of the USGS classification system in year 2000 derived from USGS Land Cover Institute, which include 24 land cover types, were used as baseline data. The land cover data of years 2010 and 2100 were predicted with the data of land conversion among different land cover types. The land conversion data were derived from land use scenario that was simulated with the model that combines Asia-Pacific Integrated Model with the global economy model (AIM/CGE) based on Representative Concentration Pathways 6 (RCP6). In the AIM/CGE model, land was treated as a production factor for agriculture, livestock, forestry, and biomass energy production. Urban land use increased due to population and economic growth, while croplands area expanded due to increasing food demand. The land cover data and underlying surface change data during $1500-2100$ can be obtained through data fusion at $0.5^{\circ} \times 0.5^{\circ}$ resolution [32].

As there is a difference in the spatial resolution and classification types between the land cover data of the USGS classification system and the RCP-based land conversion data, it is necessary to reclassify the land conversion data to the USGS classification and convert the spatial resolution to be of higher resolution (1-10 km) as the requirement of the WRF model. As it is well acknowledged that RCMs with spatial resolution at or coarser than $30 \mathrm{~km}$ are unable to produce accurate climate forecasts [33]. Higher resolution allowed the model to include the regional features and predict the regional climate with more accuracy. For example, WRF simulations can be done at a resolution of $4 \mathrm{~km}$ which allows many small scale features such as mountains, coastlines and other land use categories to be represented more accurately, which is important for our purposes [34]. In this study, we set the resolution of the land cover data to be $5 \mathrm{~km}$ in the WRF model. Taking the processing of land cover data of year 2100 as an example, first, the accumulated fraction of different kinds of land conversion in each $0.5^{\circ} \times 0.5^{\circ}$ grid from 2000 to 2100 was calculated (Figure 1). Then the dominant conversion type (with maxima conversion amount) of each grid was identified, and thereafter whether the land cover type of grids changed or not was identified through setting threshold value of the conversion rate. The threshold values were mainly set to reveal the conversion trend, as to each type of conversion, the threshold value was set to be the 50th percentile of the conversion rate. The land cover data in years 2010 and 2100 were further obtained on the basis of the land cover data of the USGS classification in year 2000 and the data of land conversion during 2000-2010 and 2000-2100, and finally these underlying surface data were transformed to grid data of $5 \mathrm{~km} \times 5 \mathrm{~km}$ through resampling.

As to the atmospheric forcing data, the fifth phase of the Coupled Model Intercomparison Project (CMIP5) produces a state-of-the-art multimodel dataset designed to advance our knowledge of climate variability and climate change $[35,36]$. The model output which is being analyzed by researchers worldwide underlies the Fifth Assessment Report of IPCC. It provides projections of future climate change on two time scales, near term (out to about 2035) and long term (out to 2100 and beyond). Model output of RCP6 such as air temperature, specific humidity, sea level pressure, eastward wind, northward wind, and geopotential height from 2000 to 2100 was used as the atmospheric forcing dataset of the WRF model. And the meteorological observation data, which were used to compare with the simulated temperature in this study, were derived from European Climate Assessment \& Dataset (http://eca.knmi.nl/dailydata/predefinedseries.php).

\subsection{The WRF Model and Scenario-Based Experiment Design}

2.2.1. WRF Model. With the development of the climate models and land surface process models, the numerical simulation has become a widely used approach to study the influence of land cover change on climate. The WRF model 
is a next generation mesoscale numerical weather prediction system that has been developed as a collaborative effort by the National Center for Atmospheric Research (NCAR), the National Oceanic and Atmospheric Administration, the National Centers for Environmental Prediction (NCEP) and the Forecast Systems Laboratory (FSL), the Air Force Weather Agency (AFWA), the Naval Research Laboratory, the University of Oklahoma, and the Federal Aviation Administration (FAA). It is a state-of-the-art atmospheric simulation system based on the Fifth-Generation Penn State/NCAR Mesoscale Model (MM5) [37]. This mesoscale model has been widely used in the simulation of the global climate [38-40] and regional climate [41]. In this paper, the WRF model based on the Eulerian mass solver was used to analyze the impacts of land cover change on the near-surface temperature in the study area. In a WRF simulation, each grid point has a land cover type based on the land cover dataset being used for the model run. The properties (surface albedo, surface emissivity, moisture availability, and surface roughness length) of each land cover type depend on the land surface model used in the WRF run. The land surface model is the component that takes care of the processes involving land-surface interactions. For the WRF runs, the parameterization scheme of physical processes in the model was set; USGS classification dataset was used to specify land cover types and their properties. To simulate land cover change conditions, all the land cover data were projected based on scenarios.

2.2.2. Experiment Design. The Advanced Research WRF (ARW-WRF Edition 3.3) was used in this study. The Lambert projection was used, with the two standard parallels both being $57^{\circ} \mathrm{N}$ and central meridian $48^{\circ} \mathrm{E}$. The spatial resolution was set to be $5 \mathrm{~km}$. The study area is located in European Russia, and it contains 192 grid points in the east-west direction and 174 grid points in the north-south direction.

The parameterization scheme of physical processes in the model (Table 1) is as follows. The Microphysics parameterization Scheme adopted the scheme introduced by Lin et al. [42]. The cumulus parameterization scheme adopted the Grell-Devenyi ensemble scheme. The boundary layer process scheme was Yonsei University (YSU) scheme. The long-wave radiation scheme and short-wave radiation scheme both were the Community Atmosphere Model (CAM) scheme, and the land surface process scheme was Noah land surface model. The boundary buffer was set to be 4 layers of grid points, and the boundary conditions adopted the relaxation scheme. The time interval of the model integration was set to be 5 minutes and that of the radiation process and cumulus convection was 30 minutes and 5 minutes, respectively. There were 27 layers in the vertical direction, and the atmospheric pressure at the top layer was $50 \mathrm{hPa}$.

The simulation schemes in this study are as follows (Table 2). The simulation was implemented with the land cover data in three years as the underlying surface. The land cover dataset of year 2000 (Figure 2) with the United States Geological Survey's (USGS) classification system was used as the baseline underlying surface data in this study. The land use datasets of years 2010 and 2100 were based on the land use/cover conversion information that was derived
TABLE 1: Parameterization scheme of physical processes in the model.

\begin{tabular}{ll}
\hline Classification of schemes & Scheme option \\
\hline $\begin{array}{l}\text { Microphysics parameterization } \\
\text { scheme }\end{array}$ & $\begin{array}{l}\text { Bulk microphysics schemes } \\
\text { introduced by Lin et al. [42] }\end{array}$ \\
$\begin{array}{l}\text { Cumulus parameterization scheme } \\
\text { Boundary layer process scheme }\end{array}$ & Grell-Devenyi ensemble \\
Long-wave radiation scheme & CAM long-wave Radiation \\
Short-wave radiation scheme & CAM short-wave Radiation \\
Land Surface process scheme & Noah land surface model \\
\hline
\end{tabular}

TABLE 2: Design of the simulation scheme.

\begin{tabular}{lcl}
\hline Simulation & $\begin{array}{c}\text { Period of } \\
\text { forcing data }\end{array}$ & $\begin{array}{l}\text { Land cover data used in the } \\
\text { WRF model }\end{array}$ \\
\hline $\begin{array}{l}\text { Control simulation: } \\
\text { year 2000 as the } \\
\text { baseline year }\end{array}$ & 2000 & $\begin{array}{l}\text { Land cover data of year } \\
2000 \text { (USGS Classification) }\end{array}$ \\
$\begin{array}{l}\text { Sensitivity simulation } \\
\text { I: year 2010 }\end{array}$ & 2010 & $\begin{array}{l}\text { Land cover data of year } \\
2010 \text { (USGS Classification } \\
\text { Based on Scenario) } \\
\text { Land cover data of year } \\
\text { Sensitivity simulation } \\
\text { II: year 2100 }\end{array}$ \\
\hline \multirow{2}{*}{2100}
\end{tabular}

from land use scenario which was simulated with AIM/CGE based on RCP6 [32]. Then the underlying surface datasets of each year were used as the input data of the WRF model to simulate the impact of land cover change on the climate change. The simulations in three years were all implemented with the meteorological forcing data as displayed in Table 2. The monthly and seasonal simulation results were compared. Firstly, the simulation results of monthly temperature in year 2010 were used to validate the ability of the WRF model to simulate the temperature change in the study area; then spatial difference between the near-surface temperature in the winter of years 2000 and 2010 was analyzed; at last the comparison between the monthly near-surface temperatures of years 2010 and 2100 was implemented.

2.3. Land Cover Change in the Study Area of European Russia. The main land cover types in the study area are the croplands (four types of croplands in USGS classification, with "Dryland Cropland and Pasture" (DCP) and "Cropland Woodland Mosaics" (CWM) dominating) and forests (four types of forests in USGS classification, with "Evergreen Needleleaf Forest" (ENF) and "Mixed Forest" (MF) dominating), accounting for about $53 \%$ and $44 \%$ of the total land area, respectively. The conversion types in the region are mainly dominated by the conversion between croplands and forests.

From 2000 to 2010, the land cover conversion is dominated by the conversion from croplands to forests (mainly from CWM type to MF type in the northern part of the study area) and conversion from forests to croplands (mainly from MF type to DCP type in the southern part of the study area) in different parts of the study area. Statistics of the dominant conversion type of each grid show that 


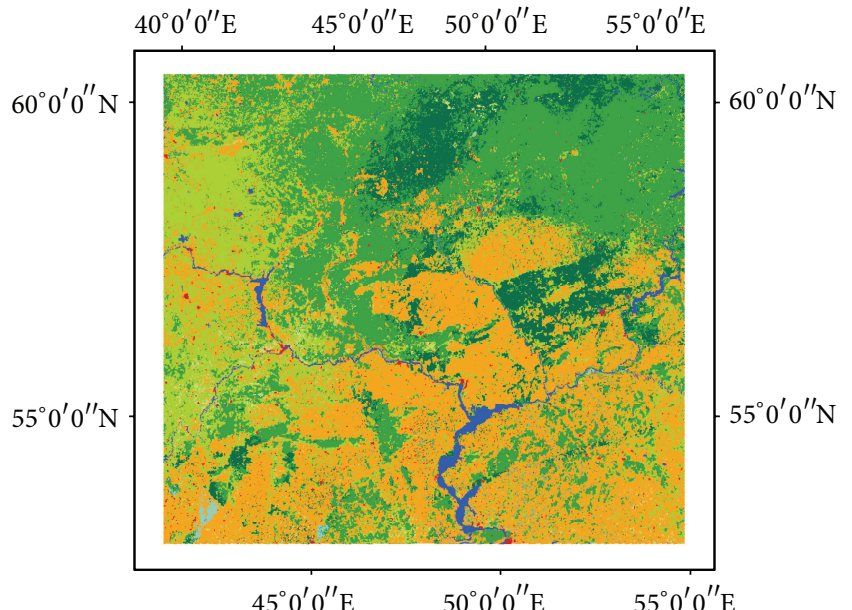

Urban and built-up land

$\square$ Dryland cropland and pasture

$\square$ Irrigated cropland and pasture

$\square$ Mixed dryland/irrigated cropland and pasture

$\square$ Cropland/grassland mosaic

$\square$ Cropland/woodland mosaic

$\square$ Grassland

$\square$ Shrubland

$\square$ Mixed shrubland/grassland

$\square$ Savanna

$\square$ Deciduous broadleaf forest

$\square$ Deciduous needleleaf forest

$\square$ Evergreen broadleaf forest

- Evergreen needleleaf forest

Mixed forest

Water bodies

$\square$ Herbaceous wetland

Wooded woodland

$\square$ Barren or sparsely vegetated

$\square$ Herbaceous tundra

$\square$ Wooded tundra

$\square$ Mixed tundra

$\square$ Bare ground tundra

$\square$ Snow or ice

FIGURE 2: Land cover of the study area in year 2000.

grids dominated by the conversion from croplands to forests account for $26.18 \%$ of all the grids in the study area and grids dominated by the conversion from forests to croplands account for $27.80 \%$ of all the grids. Besides, integrated with other types of land conversion, the percentage of forests in the total land area will decrease from $44.40 \%$ to $44.07 \%$, while that of the croplands will increase from $53.04 \%$ to $53.37 \%$. The conversion between the forests and croplands will be in balance overall during 2000-2010. However, the spatial heterogeneity of the conversion between them will lead to the change of their spatial distribution. For example, the croplands in the northern part of study area have a tendency to be converted to forests, while the scattered forests in the southern part tend to be converted to croplands (Figure 3).

According to the statistics of conversion type grids, the conversion from forests to croplands will dominate in the study area by 2100 . The grids presenting the conversion
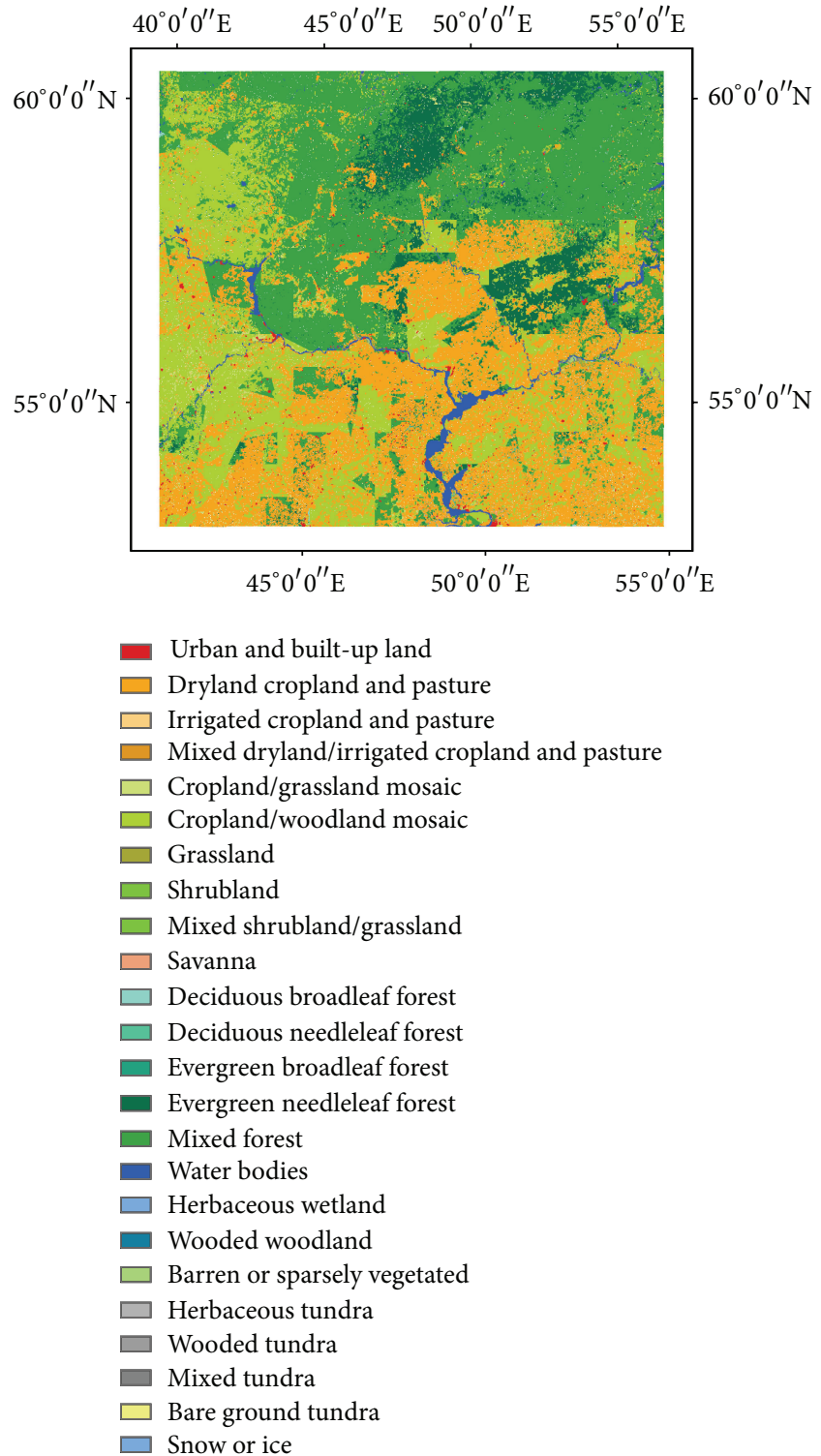

FIGURE 3: Land cover of the study area in year 2010.

from forests to croplands as the primary conversion type will account for $37.4 \%$ of all the grids. The croplands coverage will account for $72.27 \%$ of the total land area, while the forests coverage will decrease to $25.31 \%$ (Figure 4). It is indicated that there is a strong tendency of conversion from forests to croplands in this region in the future 100 years.

The coverage percentage of different land cover type in years 2000, 2010, and 2100 which was calculated based on the account of grids of each land cover type is shown in Table 3.

\section{Results}

3.1. Validation of the Simulation Result. To assess the ability of the WRF model to simulate the temperature change in the study area, we compared the simulated values of monthly average temperature with the ground-based observed values of year 2010. First, the daily average temperature was 

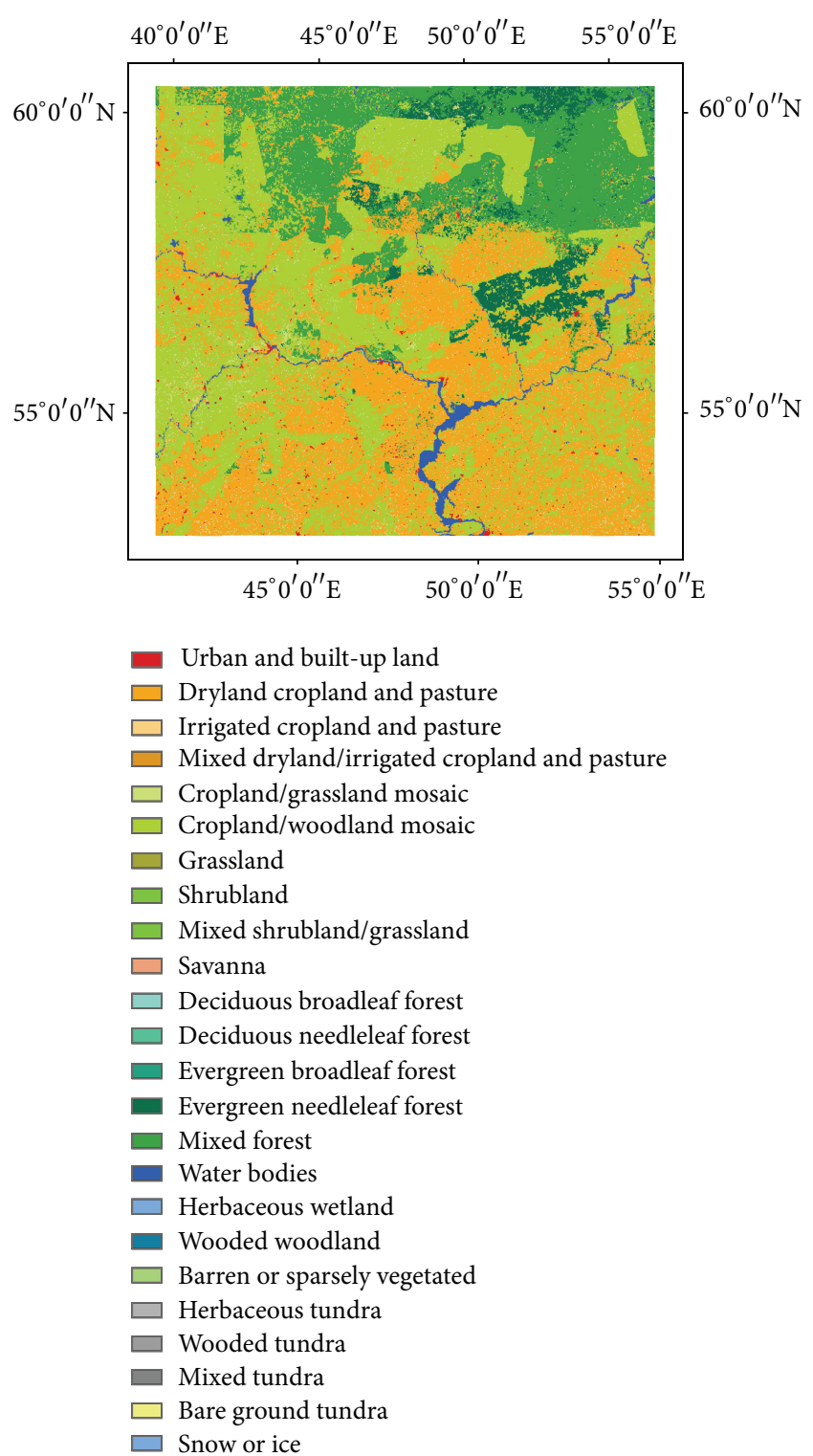

FIgURE 4: Land cover of the study area in year 2100.

simulated based on the WRF model, then it was used to calculate monthly average temperature to compare it with the ground-based observed data. As shown in Figure 5, the change trends of both simulated and observed monthly average temperatures in the study area were relatively similar, and the difference between the observed and simulated values generally fluctuates around zero. To examine whether the difference was significant or not, a paired $t$-test was conducted to test the difference between simulated values and observed values. The null hypothesis was that there was no significant difference between those two samples, and the $P$ value of the paired $t$-test was 0.9146 at the significance level of 0.05 , indicating that there was no significant difference between the simulated values and observation values. Thus, it can be identified that the WRF model has the ability to simulate the temperature change.

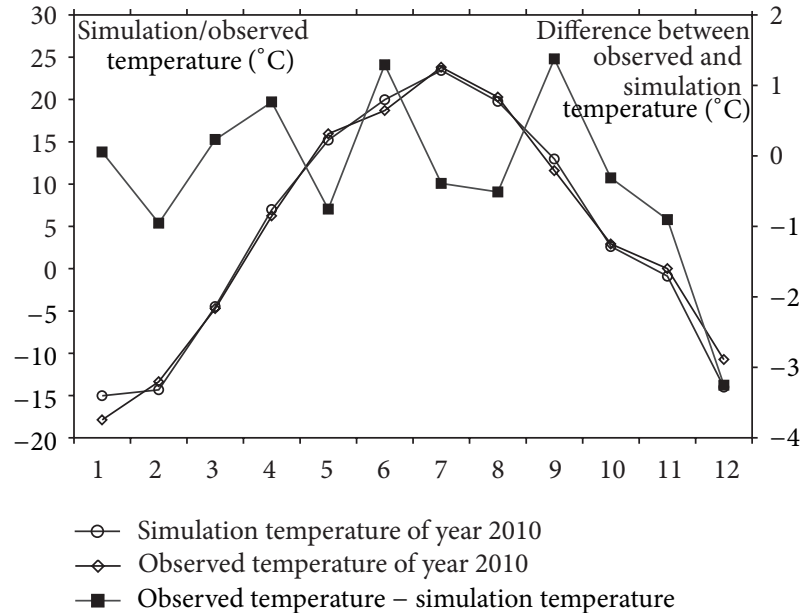

FIGURE 5: Comparison of simulated and observed values of the monthly average near-surface temperature at 2 meters above the ground of the study area.

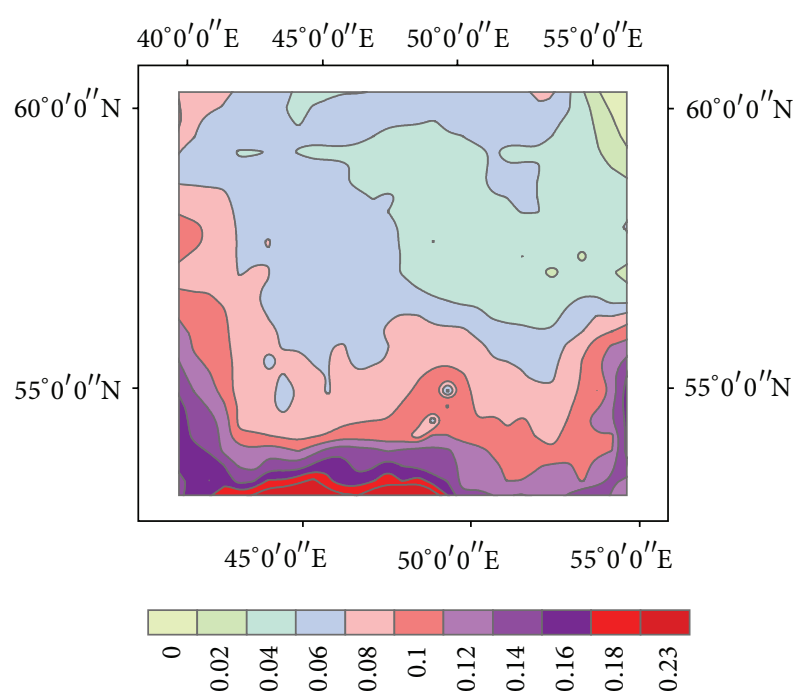

FIGURE 6: Difference of simulated monthly average temperature in the winter between year 2000 and 2010 (unit: ${ }^{\circ} \mathrm{C}$ ) in the study area.

3.2. Analysis of Temperature Change. As a result of the conversion between croplands and forests from 2000 to 2010, the simulated monthly average temperature during the winter (December, January, and February) increased in most of the parts of the study area compared with that in year 2000 (Figure 6). The spatial pattern of the temperature change during winter corresponded to the land cover and land cover change. The average temperature in the winter generally increased in the regions which are mainly covered by croplands and where the boreal forest expands. In the southern part of the study area, which is mainly covered by DCP type cropland, the forests were converted to croplands, and the temperature increment was relatively higher. The average temperature increment generally declines as the distance to regions mainly covered by the forests decreases. In general, the land cover change in the study area is almost in balance from 2000 to 2010; there was very slight change in the average 
TABLE 3: Coverage percentage of different land cover type (\%).

\begin{tabular}{|c|c|c|c|}
\hline \multirow{2}{*}{ USGS land cover classification } & \multicolumn{3}{|c|}{ Coverage percentage } \\
\hline & 2000 & 2010 & 2100 \\
\hline (1) Urban and built-up land & 0.65 & 0.59 & 0.62 \\
\hline (2) Dryland cropland and pasture & 31.07 & 28.59 & 32.21 \\
\hline (3) Irrigated cropland and pasture & 0.00 & 0.00 & 0.00 \\
\hline (5) Cropland/grassland mosaic & 1.07 & 0.78 & 1.01 \\
\hline (6) Crop/woodland Mosaic & 20.90 & 24.00 & 39.05 \\
\hline Sum of cropland & 53.04 & 53.37 & 72.27 \\
\hline (7) Grassland & 0.18 & 0.12 & 0.03 \\
\hline (8) Shrub land & 0.01 & 0.01 & 0.01 \\
\hline (10) Savanna & 0.12 & 0.07 & 0.00 \\
\hline (11) Deciduous broadleaf forest & 0.24 & 0.06 & 0.01 \\
\hline (12) Deciduous broadleaf forest & 0.27 & 0.13 & 0.02 \\
\hline (14) Evergreen needleleaf forest & 9.87 & 8.54 & 6.76 \\
\hline (15) Mixed forest & 33.85 & 35.33 & 18.51 \\
\hline (16) Water bodies & 1.74 & 1.74 & 1.74 \\
\hline Sum of Forests & 44.22 & 44.07 & 25.30 \\
\hline (18) Wooded wetland & 0.00 & 0.00 & 0.00 \\
\hline (19) Barren or sparsely vegetated & 0.02 & 0.02 & 0.01 \\
\hline (21) Wooded tundra & 0.00 & 0.00 & 0.00 \\
\hline (22) Mixed tundra & 0.01 & 0.01 & 0.01 \\
\hline Total & 100 & 100 & 100 \\
\hline
\end{tabular}

temperature in the winter (no more than $0.023^{\circ} \mathrm{C} /$ year), and the spatial distribution of temperature change corresponds to land cover and land cover change.

The land cover change in the study area in year 2100 is mainly characterized by the conversion from forests to croplands, and it will lead to change of the near-surface temperature. The annual temperature will decline, while the monthly average temperature will increase from February to June and decrease from July to January (Figure 7). In the boreal forest region, the temperature change mainly results from the change of albedo due to snow masking [9]. As snow covers the surface and boreal forests are converted to croplands, the albedo of the land surface will increase and the net surface solar radiation will reduce; thus it will lead to the cooling effect, which offsets the warming effect due to the decrease of evaporation-transpiration. Therefore, near-surface temperature during the winter will change most intensively, decreasing by $1.81^{\circ} \mathrm{C}$ on average. In the northern hemisphere, solar radiation begins to strengthen in June and becomes the strongest around July and August. The conifer forests (needle-leaf forests) have lower evapotranspiration rate (defined as ratio of latent heat flux to available energy) than the deciduous broadleaf forests in the summer, which can lead to the higher rates of sensible heat flux [3]. From 2010 to 2100 , most evergreen needleleaf forests will be converted to croplands, and thus the cooling effect due to the albedo increase is also stronger than the warming effect due to the decrease of evapotranspiration in the previous needle-leaf forest area during July and August and consequently makes the average temperature decrease by $0.30^{\circ} \mathrm{C}$. While, in the spring, snow will melt and the solar radiation is not very high, the warming effect due to the evapotranspiration reduction of evergreen needleleaf forests cannot be offset by the cooling effect due to the increase of surface albedo, and consequently the monthly average temperature will increase by $0.86^{\circ} \mathrm{C}$ in the spring. In general, the result indicated that the high albedo resulting from deforestation of boreal forests has negative impacts on the temperature; that is, boreal deforestation will make the temperature decrease, especially during the snow season.

\section{Conclusions and Discussions}

In this paper, the WRF model was used to study the impacts of boreal deforestation on the near-surface temperature in the European Russia. Based on the analysis of the land cover data of years 2000, 2010, and 2100, it was shown that the land cover change in the study area was mainly characterized by the conversion between forests and croplands. During $2000-2010$, the croplands increased by $0.33 \%$ and the forests decreased by $0.15 \%$, while other land cover types changed slightly. The conversion from croplands to forests mainly appeared in the northern part which was previously dominated by forests, while the conversion from scattered forests to croplands mainly appeared in the southern part which was mainly dominated by croplands. By year 2100, there will be significant land cover change; the percentage of forests in the total land area will decrease from $44.22 \%$ to $25.3 \%$, indicating that about half of the forests will be coveted to croplands.

The results indicate that the simulation result with the WRF model can match the monthly average temperature change with the observed temperature in the study area. 


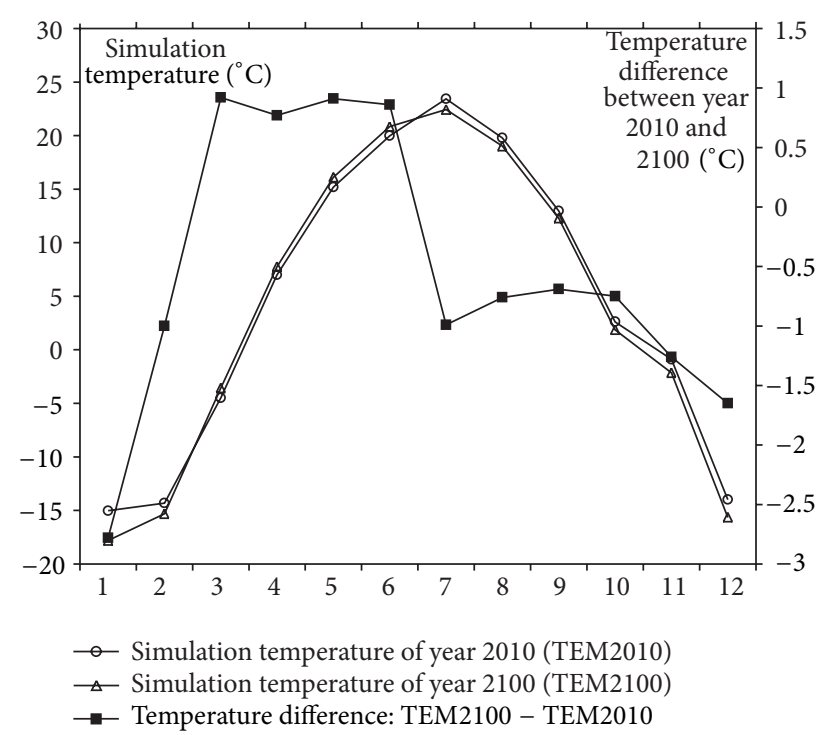

FIGURE 7: Comparison of simulated monthly average temperature at 2 meters above the ground in year 2010 and year 2100 in the study area.

The land cover change in the study area, which was mainly characterized by the conversion between boreal forests and croplands, will lead to significant change of the nearsurface temperature, especially in year 2100. It will make the regional near-surface temperature decrease by $0.58^{\circ} \mathrm{C}$ in future 100 years $\left(0.0058^{\circ} \mathrm{C} /\right.$ year on average $)$ with the temperature change varying greatly in different seasons. The temperature changes most drastically in the winter, with an average decrease of $1.81^{\circ} \mathrm{C}$. And the temperature will decrease by $0.30^{\circ} \mathrm{C}$ in the summer, while in the spring it will increase by $0.87^{\circ} \mathrm{C}$. The temperature change is mainly due to the increase of surface albedo caused by boreal deforestation, which offsets the warming effect due to evapotranspiration reduction of forests.

The results of this study basically reveal the impacts of boreal deforestation on regional climate changes, which are closely related to human activities, but there are still some uncertainties about the influence of the future land cover change since only biogeophysical effects were taken into consideration in the WRF model, without considering the biochemical effects through some other key influencing factors, such as carbon emission. Since the impacts of land cover change are very complex, it is still necessary to carry out more indepth researches on a series of issues such as the improvement of the climate model and combination of biochemical and biophysical models, which take both the biogeophysical and biogeochemical processes into account. In addition, there are still some aspects that should be improved to more accurately detect the impact of deforestation on climate changes. First, it is still necessary to further explore the data integration between the land cover data of USGS classification and the RCP-based land conversion data since there is some difference between them. Although the main trend of land conversion can be identified, there still exist some uncertainties about its impacts on the future climate change. Second, there are many factors that may influence the climate change, and it is necessary to do some sensitivity experiments to detect the main factors and minimize the uncertainty.

\section{Conflict of Interests}

The authors declare that they have no conflict of interests regarding the publication of this paper.

\section{Acknowledgments}

This research was supported by the Key Project funded by the Chinese Academy of Sciences (no. KZZD-EW-08), National Key Programme for Developing Basic Science in China (no. 2010CB950900), and the External Cooperation Program of the Chinese Academy of Sciences (no. GJHZ1312).

\section{References}

[1] S. Solomon, D. Qin, M. Manning et al., Climate Change 2007: The Physical Science Basis, Cambridge University Press, New York, NY, USA, 2007.

[2] J. J. Feddema, K. W. Oleson, G. B. Bonan et al., "Atmospheric science: the importance of land-cover change in simulating future climates," Science, vol. 310, no. 5754, pp. 1674-1678, 2005.

[3] G. B. Bonan, "Forests and climate change: forcings, feedbacks, and the climate benefits of forests," Science, vol. 320, no. 5882, pp. 1444-1449, 2008.

[4] G. B. Bonan, Ecological Climatology: Concepts and Applications, Cambridge University Press, 2002.

[5] M. H. Costa and J. A. Foley, "Combined effects of deforestation and doubled atmospheric $\mathrm{CO} 2$ concentrations on the climate of Amazonia," Journal of Climate, vol. 13, no. 1, pp. 18-34, 2000.

[6] R. E. Dickinson and A. Henderson-Sellers, "Modelling tropical deforestation: a study of GCM land/surface parametrizations," Quarterly Journal, vol. 114, no. 480, pp. 439-462, 1988.

[7] N. Gedney and P. J. Valdes, "The effect of Amazonian deforestation on the northern hemisphere circulation and climate," Geophysical Research Letters, vol. 27, no. 19, pp. 3053-3056, 2000.

[8] A. Henderson-Sellers, R. E. Dickinson, T. B. Durbidge, P. J. Kennedy, K. McGuffie, and A. J. Pitman, “Tropical deforestation: modeling local- to regional-scale climate change," Journal of Geophysical Research, vol. 98, no. 4, pp. 7289-7315, 1993.

[9] S. Bathiany, M. Claussen, V. Brovkin, T. Raddatz, and V. Gayler, "Combined biogeophysical and biogeochemical effects of largescale forest cover changes in the MPI earth system model," Biogeosciences, vol. 7, no. 5, pp. 1383-1399, 2010.

[10] E. L. Davin and N. de Noblet-Ducoudre, "Climatic impact of global-scale Deforestation: radiative versus nonradiative processes," Journal of Climate, vol. 23, no. 1, pp. 97-112, 2010.

[11] G. Bala, K. Caldeira, M. Wickett et al., "Combined climate and carbon-cycle effects of large-scale deforestation," Proceedings of the National Academy of Sciences of the United States of America, vol. 104, no. 16, pp. 6550-6555, 2007.

[12] X. Lee, M. L. Goulden, D. Y. Hollinger et al., "Observed increase in local cooling effect of deforestation at higher latitudes," Nature, vol. 479, no. 7373, pp. 384-387, 2011.

[13] R. A. Pielke Sr., G. Marland, R. A. Betts et al., "The influence of land-use change and landscape dynamics on the climate system: 
relevance to climate-change policy beyond the radiative effect of greenhouse gases," Philosophical Transactions of the Royal Society A, vol. 360, no. 1797, pp. 1705-1719, 2002.

[14] P. J. Lawrence and T. N. Chase, "Investigating the climate impacts of global land cover change in the community climate system model," International Journal of Climatology, vol. 30, no. 13, pp. 2066-2087, 2010.

[15] E. Ellis and R. Pontius, "Land-use and land-cover change," Encyclopedia of Earth, Environmental Information Coalition, National Council for Science and the Environment, Washington, DC, USA, 2007, http://www.eoearth.org/article/ Landuse_and_land-cover_change.

[16] G. B. Bonan, D. Pollard, and S. L. Thompson, "Effects of boreal forest vegetation on global climate," Nature, vol. 359, no. 6397, pp. 716-718, 1992.

[17] V. Brovkin, A. Ganopolski, M. Claussen, C. Kubatzki, and V. Petoukhov, "Modelling climate response to historical land cover change," Global Ecology and Biogeography, vol. 8, no. 6, pp. 509517, 1999.

[18] B. Govindasamy, P. B. Duffy, and K. Caldeira, "Land use changes and Northern Hemisphere cooling," Geophysical Research Letters, vol. 28, no. 2, pp. 291-294, 2001.

[19] P. K. Snyder, C. Delire, and J. A. Foley, "Evaluating the influence of different vegetation biomes on the global climate," Climate Dynamics, vol. 23, no. 3-4, pp. 279-302, 2004.

[20] R. A. Pielke Sr., R. Avissar, M. Raupach, A. J. Dolman, X. Zeng, and A. S. Denning, "Interactions between the atmosphere and terrestrial ecosystems: influence on weather and climate," Global Change Biology, vol. 4, no. 5, pp. 461-475, 1998.

[21] I. S. Kang, K. Jin, B. Wang et al., "Intercomparison of the climatological variations of Asian summer monsoon precipitation simulated by 10 GCMs," Climate Dynamics, vol. 19, no. 5-6, pp. 383-395, 2002.

[22] V. Brovkin, M. Claussen, E. Driesschaert et al., "Biogeophysical effects of historical land cover changes simulated by six Earth system models of intermediate complexity," Climate Dynamics, vol. 26, no. 6, pp. 587-600, 2006.

[23] E. T. Yu, H. J. Wang, and J. Q. Sun, "A quick report on a dynamical downscaling simulation over China using the nested model," Atmospheric and Oceanic Science Letters, vol. 3, no. 6, pp. 325-329, 2010.

[24] H. Von Storch, E. Zorita, and U. Cubasch, "Downscaling of global climate change estimates to regional scales: an application to Iberian rainfall in wintertime," Journal of Climate, vol. 6, no. 6, pp. 1161-1171, 1993.

[25] J. M. Jin, N. L. Miller, and N. Schlegel, "Sensitivity study of four land surface schemes in the WRF model," Advances in Meteorology, vol. 2010, Article ID 167436, 11 pages, 2010.

[26] P. Caldwell, H.-N. S. Chin, D. C. Bader, and G. Bala, "Evaluation of a WRF dynamical downscaling simulation over California," Climatic Change, vol. 95, no. 3-4, pp. 499-521, 2009.

[27] C. V. Srinivas, D. Hariprasad, D. V. Bhaskar Rao, Y. Anjaneyulu, R. Baskaran, and B. Venkatraman, "Simulation of the Indian summer monsoon regional climate using advanced research WRF model," International Journal of Climatology, vol. 33, no. 5, pp. 1195-1210, 2013.

[28] M. Baumann, M. Ozdogan, T. Kuemmerle, K. J. Wendland, E. Esipova, and V. C. Radeloff, "Using the Landsat record to detect forest-cover changes during and after the collapse of the Soviet Union in the temperate zone of European Russia," Remote Sensing of Environment, vol. 124, pp. 174-184, 2012.
[29] M. C. Hansen, S. V. Stehman, and P. V. Potapov, "Quantification of global gross forest cover loss," Proceedings of the National Academy of Sciences of the United States of America, vol. 107, no. 19, pp. 8650-8655, 2010.

[30] P. Potapov, S. Turubanova, and M. C. Hansen, "Regional-scale boreal forest cover and change mapping using Landsat data composites for European Russia," Remote Sensing of Environment, vol. 115, no. 2, pp. 548-561, 2011.

[31] F. Wu, J. Y. Zhan, H. M. Yan, C. C. Shi, and J. Huang, "Land cover mapping based on multisource spatial data mining approach for climate simulation: a case study in the farming-pastoral ecotone of North China," Advances in Meteorology, vol. 2013, Article ID 520803, 12 pages, 2013.

[32] G. C. Hurtt, L. P. Chini, S. Frolking et al., "Harmonization of land-use scenarios for the period 1500-2100: 600 years of global gridded annual land-use transitions, wood harvest, and resulting secondary lands," Climatic Change, vol. 109, no. 1, pp. 117-161, 2011.

[33] J. Jin and N. L. Miller, "Analysis of the impact of snow on daily weather variability in mountainous regions using MM5," Journal of Hydrometeorology, vol. 8, no. 2, pp. 245-258, 2007.

[34] R. Mawalagedara and R. J. Oglesby, "The climatic effects of deforestation in south and southeast Asia," Deforestation Around the World, 2011.

[35] N. S. Keenlyside, M. Latif, J. Jungclaus, L. Kornblueh, and E. Roeckner, "Advancing decadal-scale climate prediction in the North Atlantic sector," Nature, vol. 453, no. 7191, pp. 84-88, 2008.

[36] K. E. Taylor, R. J. Stouffer, and G. A. Meehl, "An overview of CMIP5 and the experiment design," Bulletin of the American Meteorological Society, vol. 93, no. 4, pp. 485-498, 2012.

[37] M. A. Hernandez-Ceballos, J. A. Adame, J. P. Bolivar, and B. A. De La Morena, "A mesoscale simulation of coastal circulation in the Guadalquivir valley (southwestern Iberian Peninsula) using the WRF-ARW model," Atmospheric Research, vol.124, pp. 1-20, 2013.

[38] J. Chen, P. Zhao, H. Liu, and X. Guo, "Modeling impacts of vegetation in western China on the summer climate of northwestern China," Advances in Atmospheric Sciences, vol. 26, no. 4, pp. 803-812, 2009.

[39] A. Garcia-R, T. Schoenemeyer, A. Jazcilevich D., G. RuizSuárez, and V. Fuentes-Gea, "Implementation of the multiscale climate chemistry model (MCCM) for Central Mexico," in Proceedings of the International Conference on Air Pollution, pp. 71-78, July 2000.

[40] A. D. Jazcilevich, A. R. García, and L. G. Ruíz-Suárez, "A modeling study of air pollution modulation through land-use change in the Valley of Mexico," Atmospheric Environment, vol. 36, no. 14, pp. 2297-2307, 2002.

[41] M. Mohan and S. Bhati, "Analysis of WRF model performance over subtropical region of Delhi, India," Advances in Meteorology, vol. 2011, Article ID 621235, 13 pages, 2011.

[42] Y. L. Lin, R. D. Farley, and H. D. Orville, "Bulk parameterization of the snow field in a cloud model," Journal of Climate and Applied Meteorology, vol. 22, no. 6, pp. 1065-1092, 1983. 

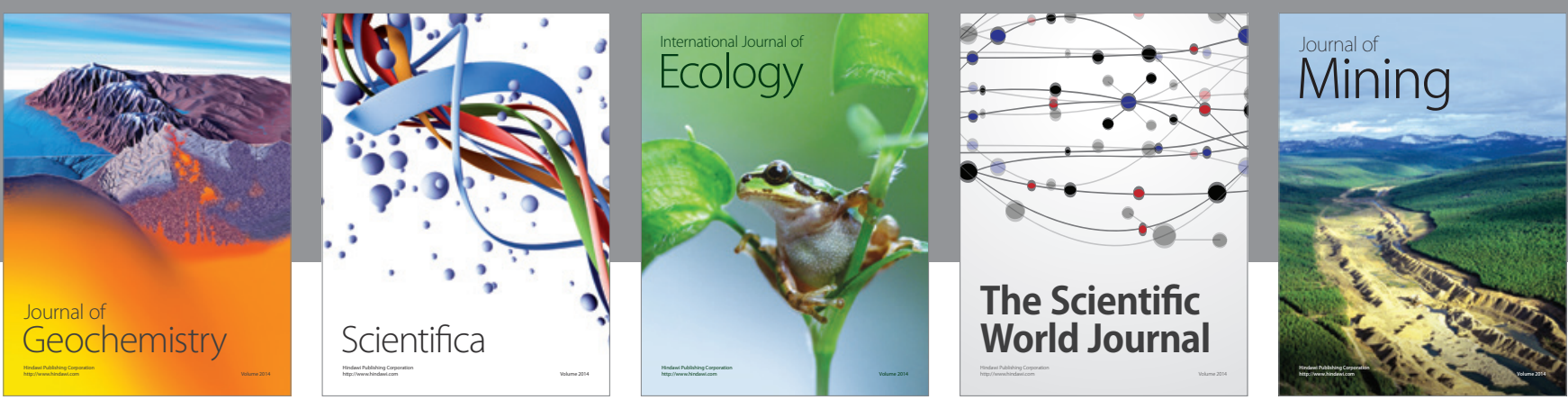

The Scientific World Journal
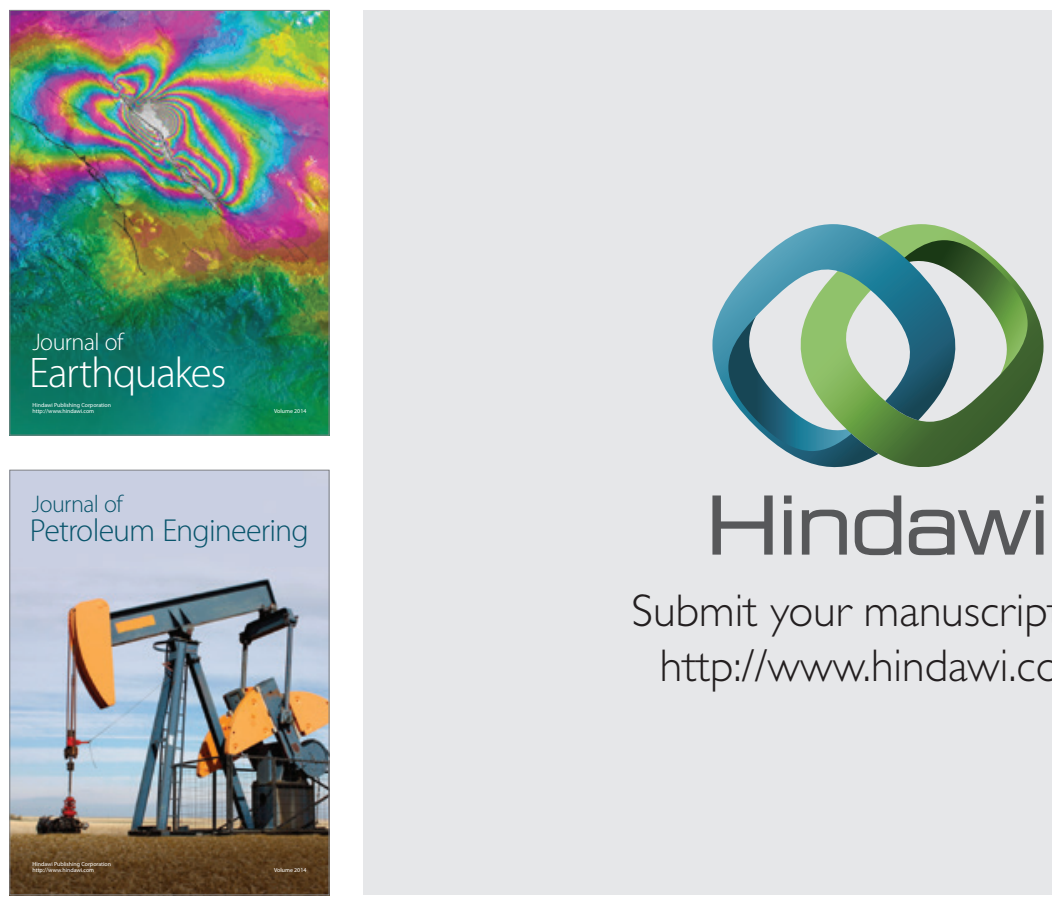

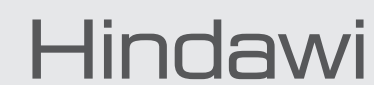

Submit your manuscripts at

http://www.hindawi.com
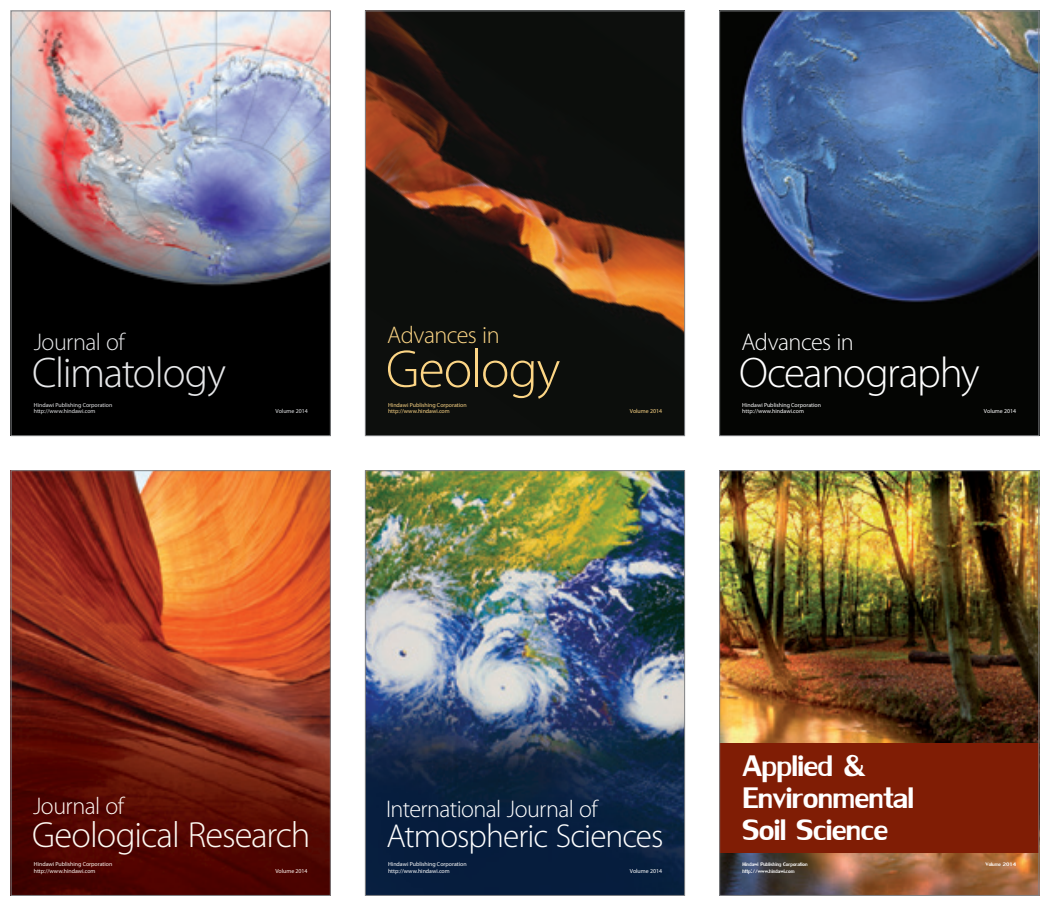
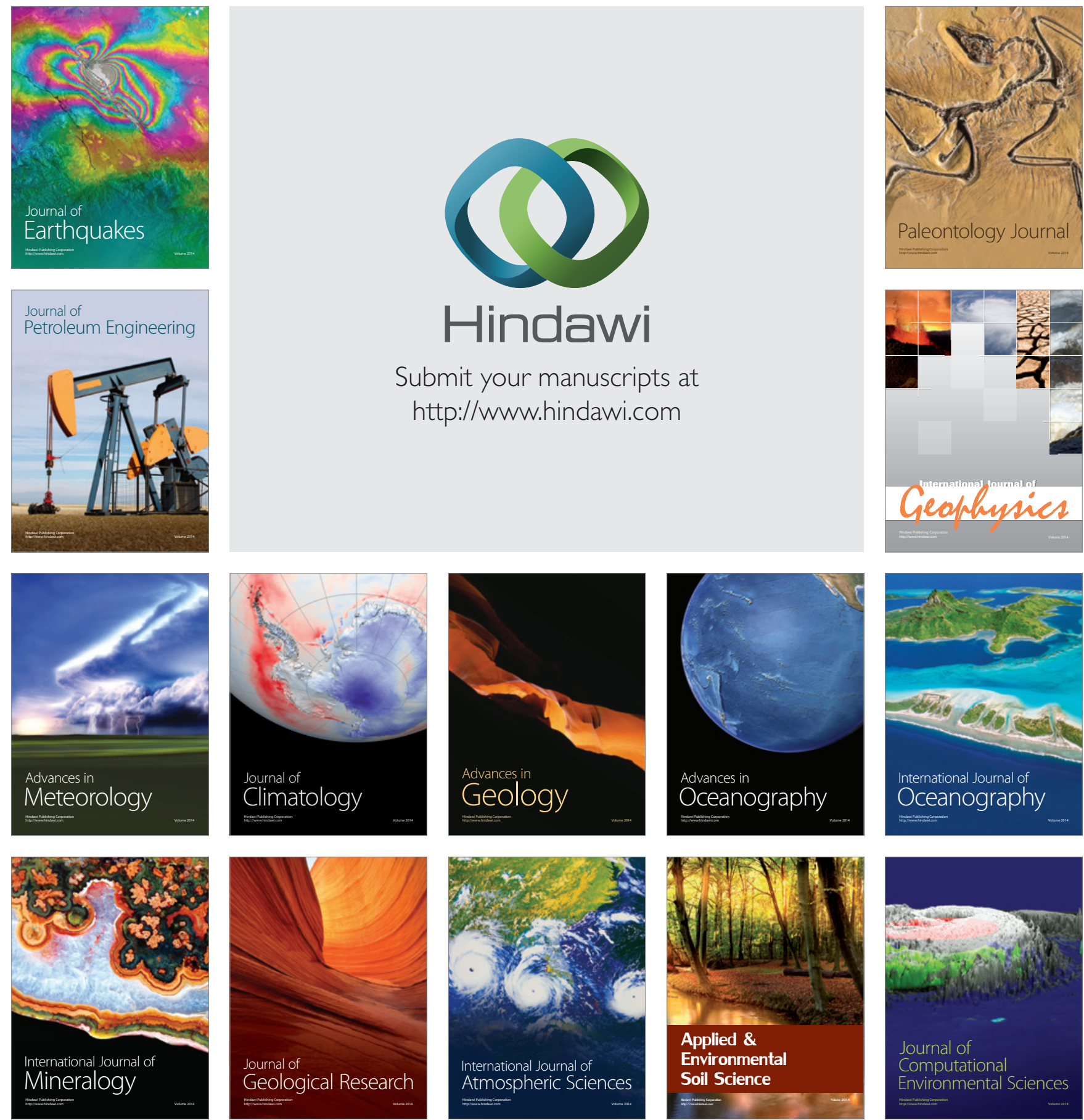